\title{
Editorial
}

\section{Financial crises and regulatory responses}

International Journal of Disclosure and Governance (2012) 9, 203-205. doi:10.1057/jdg.2012.9

It is perfectly obvious that the financial dislocations of 2007-2009 were of global significance, however they may ultimately be characterized in the retrospective view that will be possible only some years hence. There are, nonetheless, and will continue for some time to be, uncertainties and disagreements, vigorously asserted, about what were the essential causes of those dislocations. Were they the result of artificially low interest rates maintained as such by governmental authorities? Faulty governmental planning? Inadequate risk management in the private sector? Insufficient regulation? Poorly executed regulation? Or some combination of these and other inputs? We will probably never find agreement on the answers to those and related questions, and yet some form of regulatory response was virtually compelled. In the modern day of instant global communications the popular demand for action was a call the political class could not allow to go unheeded. In the United States, the key Congressional response - adoption of the Dodd-Frank Wall Street Reform and Consumer Protection Act in 2010 - preceded by several months the results of the principal Congressional inquiry into the causes - the supposedly nonpartisan report of the Financial Crisis Inquiry Commission in 2011 - technically, the 'Final Report of the National Commission on the Causes of the Financial and Economic Crisis in the United States'. (We say supposedly nonpartisan because although it was appointed with a view to nonpartisanship, the ultimate publication included a 'Commission report' with two dissenting reports, reflecting in aggregate 4 of the 10 Commission members, so that the final result was in fact quite partisan. There was in fact no nonpartisan consensus.) In other countries, the pattern is similar with 'reforms' being hurriedly put into place, perhaps reflecting more an effort to calm the electorate than any reasonable hope of accomplishing effective change. As is the nature of such things once they enter the political sphere, 'reform' movements gained a momentum all their own. Various elected representatives sought to take advantage of the opportunity, sometimes successfully, to include among the reforms pet projects they had earlier endorsed. Thus, for example, Europe considers seriously a financial transaction tax that could barely be justified as any sort of a response to the crisis.

Recognizing the nature of these events, we planned this special edition of the International Journal of Disclosure and Governance with a view to gathering in one place some of the commentary that we knew would be forthcoming. In the event, our hopes were exceeded. Of the many articles submitted, those our panels found appropriate for inclusion were considerably greater than our page limit for the special edition, which is this Number 3 of Volume 9; additional articles will be included in the forthcoming issue Number 4.

No particular humility is needed to recognize that the articles we have collected and publish here do not exhaust the subject. Indeed, we can do no more than hope that 
this modest addition to the literature, collected in this issue and the next, will prove a useful contribution (although that hope we do maintain, with every expectation that it will be satisfied). Inevitably - and particularly as what was the private financial sector crisis in the latter part of the first decade of the new millennium morphs into the more broad public sector debt crisis of the second decade - the world, and the financial markets in particular, are in for years of uncertainty. We can identify many of the things that happened in the build-up to the world as it existed in 2007, when, as Reinhart and Rogoff (2009) have observed, the International Monetary Fund comforted us 'that risks to the global economy had become extremely low and that, for the moment, there were no great worries'. Ascertaining which of those things that happened were critical to the breakdown that followed is an impossible task. In the modern, global, complex economy the various intricate relationships between and among variables are such as to defy analysis with any certainty. That economy is unquestionably chaotic and we need to be very careful in claiming to have determined a specific cause for any given result; we need to be particularly careful if we dare move from claiming a causal connection to claiming primacy of that cause.

That does not mean, however, that we cannot usefully examine likely relationships and come to some valid conclusions. We cannot predict weather with any certainty, but we can reasonably come to conclusions as to whether it is sensible to carry an umbrella or unnecessary on any given day.

Sir Howard Davies' article, leading off the issue, may merit special attention. As one who has been a major participant in many of the debates regarding regulatory attention to the financial sector over the last several years (and has had a ringside seat for those few in which he was not a major participant), his observations are important. His article fairly assesses the progress to date in generating an appropriate regulatory response to the financial crisis at a global level, a European level and a national (UK) level; his assessment is not encouraging to those who would see a need, and an opportunity, for meaningful corrections in a deficient regulatory structure. On the other hand, he is quick to point out that many of the failures that led to the crisis were human failings. As he might point out, in the United States in 2009 there were over 6000 reported bank robberies. ${ }^{1}$ One should not, from that data, leap to the assumption that the United States should change its laws regarding bank robberies or make adjustments to its bank regulatory regime. Sometimes a perfectly appropriate regulatory structure, administered by human beings, fails to lead to satisfactory regulatory results.

An entirely appropriate sense of decorum precludes our commenting on the piece by Simon Lorne. Readers will think of it what they will.

Banks were, of course, at the center of the financial crisis (as we shall term it), and the third original article in this number is Konstantinos Lapis' ambitious presentation of a proposed regulatory framework for application to the banking sector, based on Eurozone banks - banks within the Economic and Monetary Union of the European Union.

Finally, Shann Turnbull and Michael Pirson raise the fascinating question whether network governance (as they perceive it) might have made possible the prevention of the crisis or, at the least, detection of the relevant issues at an earlier stage, with appropriate corrective action. In doing so, they visit issues Dr. Turnbull has addressed in earlier articles (and this Journal has touched upon in a variety of articles). They find fault, among other things, with a centralized control system - both in the specific firm and in the regulatory apparatus - that could be improved with a governance system that includes a distributed network of constituencies. While such a networked arrangement might also have failed to prevent the crisis (as might have any governance structure) the authors perceive it as the most likely structure to succeed in such circumstances. All we 
can say with certainty is that the governance structures in place in 2007 were demonstrably insufficient to prevent the crisis.

Further articles, completing the special issue, will be found in the next following issue of the Journal. We do not humour ourselves that this collection of thoughtful pieces will illuminate the previously dark path to an appropriate regulatory structure. We do, however, hope that they will prove useful in what will inevitably be a long and continuing path of what we optimistically expect to be regulatory improvements.

\section{NOTE}

1 www.fbi.gov/about-us/investigate/vc_maj orthefts/bankrobbery, last accessed 29 May 2012 .

\section{REFERENCE}

Reinhart, C.M. and Rogoff, K.S. (2009) This Time is Different. New Jersey: Princeton University Press, p. 214.

James Bicksler Simon M. Lorne Special Edition Editors 